\title{
Patterns of resistance development with integrase inhibitors in HIV
}

\author{
This article was published in the following Dove Press journal: \\ Infection and Drug Resistance \\ 22 February 20II \\ Number of times this article has been viewed
}

\author{
Jean L Mbisa \\ Supang A Martin \\ Patricia A Cane \\ Virus Reference Department, \\ Microbiology Services, Health \\ Protection Agency, London, UK
}

Correspondence: Jean L Mbisa Virus Reference Department, Microbiology Services, Health Protection Agency, 61 Colindale Avenue, London NW9 5EQ, UK

$\mathrm{Tel}+4402083276470$

Fax +440208200 I569

Email tamyo.mbisa@hpa.org.uk

\begin{abstract}
Raltegravir, the only integrase (IN) inhibitor approved for use in HIV therapy, has recently been licensed. Raltegravir inhibits HIV-1 replication by blocking the IN strand transfer reaction. More than 30 mutations have been associated with resistance to raltegravir and other IN strand transfer inhibitors (INSTIs). The majority of the mutations are located in the vicinity of the IN active site within the catalytic core domain which is also the binding pocket for INSTIs. High-level resistance to INSTIs primarily involves three independent mutations at residues Q148, N155, and Y143. The mutations significantly affect replication capacity of the virus and are often accompanied by other mutations that either improve replication fitness and/or increase resistance to the inhibitors. The pattern of development of INSTI resistance mutations has been extensively studied in vitro and in vivo. This has been augmented by cell-based phenotypic studies and investigation of the mechanisms of resistance using biochemical assays. The recent elucidation of the structure of the prototype foamy virus IN, which is closely related to HIV-1, in complex with INSTIs has greatly enhanced our understanding of the evolution and mechanisms of IN drug resistance.
\end{abstract}

Keywords: raltegravir, elvitegravir, integrase inhibitors, HIV, drug resistance

\section{The management of HIV-I infection and drug resistance}

Over 20 antiretroviral drugs (ARVs) have been licensed for the treatment of HIV-1 infection in the past 25 years. ${ }^{1}$ This has significantly improved the prognosis of HIV-infected individuals and reduced the mortality and morbidity rates worldwide., ${ }^{2,3}$ The initial class of drugs approved for HIV-1 therapy were the nucleoside reverse transcriptase inhibitors (NRTIs) which are nucleoside analogs that inhibit DNA synthesis by acting as chain terminators. ${ }^{4}$ Subsequently, further classes of ARVs with different inhibitory mechanisms and/or targets were approved for use against HIV-1, these being non-NRTIs and protease inhibitors (PIs). ${ }^{5,6}$ All three classes target viral enzymes required for HIV-1 viral replication, namely reverse transcriptase and protease. Therefore, it is not surprising that drug-resistant variants eventually emerge against these agents due to HIV's high mutation rate and lack of a proofreading mechanism. The occurrence of drug resistance was a particular problem in the early years of ARV therapy when the drugs were used separately. This led to the idea of using no less than three different drugs belonging to at least two different classes to increase the genetic barrier to resistance development in what is termed highly active antiretroviral therapy (HAART). 
Nonetheless, the emergence of drug-resistant HIV-1 variants in patients undergoing HAART remains a major reason for treatment failure in HIV-1 therapy. Several factors contribute to treatment failure in the era of HAART, and these include poor adherence due to adverse effects associated with the drugs, high pill burden, or irregular supply of the ARVs particularly in resource-poor countries. In addition, the transmission of drug-resistant viral strains can compromise and limit the effectiveness of first-line treatment regimens. The past few years have seen the introduction of three new classes of ARVs and second-generation drugs or variants of the original classes, such as the NRTI-variant tenofovir, which possess different inhibitory mechanisms and/or fewer adverse effects. The three new classes are fusion inhibitors, entry inhibitors, and integrase (IN) inhibitors. This review focuses on the pattern of resistance development to IN inhibitors as currently understood at the molecular and structural level.

\section{HIV-I IN and integration}

Following entry of HIV into a host cell, the virus synthesizes a double-stranded (ds) DNA copy of its RNA genome. The viral DNA is then irreversibly inserted into the host genome in a process called integration. ${ }^{7,8}$ This is a defining step in the virus life cycle as it establishes a perpetual source of viral progeny for the lifetime of the cell. Integration is mediated by the virally encoded enzyme IN, and targeting this protein or its actions is a useful antiviral strategy. ${ }^{9-13}$ IN performs two main enzymatic reactions to facilitate the integration of HIV DNA into the host genome. The first reaction, termed 3' processing, prepares the viral DNA ends for insertion into target DNA by removing a pair of nucleotides at the $3^{\prime}$ end of both viral DNA strands (Figure 1). This exposes a $3^{\prime}$ hydroxyl group on the terminal adenosine of the conserved CA dinucleotide. The $3^{\prime}$ processing occurs in the cytoplasm within a high-molecular-weight preintegration complex (PIC) made up of viral DNA together with viral and cellular proteins. ${ }^{14-18}$ The $3^{\prime}$ processing step is followed by the active transfer of the PIC into the nucleus, a move facilitated by the interaction of the PIC with nucleopore complex proteins. ${ }^{19}$

Following nuclear transfer, IN performs the second of its enzymatic reactions, namely strand transfer (Figure 1). The exposed 3' hydroxyl groups at the viral DNA ends are used to attack a pair of phosphodiester bonds in the target DNA at sites that are five base pairs (bp) apart, resulting in ligation of the viral DNA strands to host cell genomic DNA. Finally, the unpaired viral CA dinucleotides on the nonligated viral

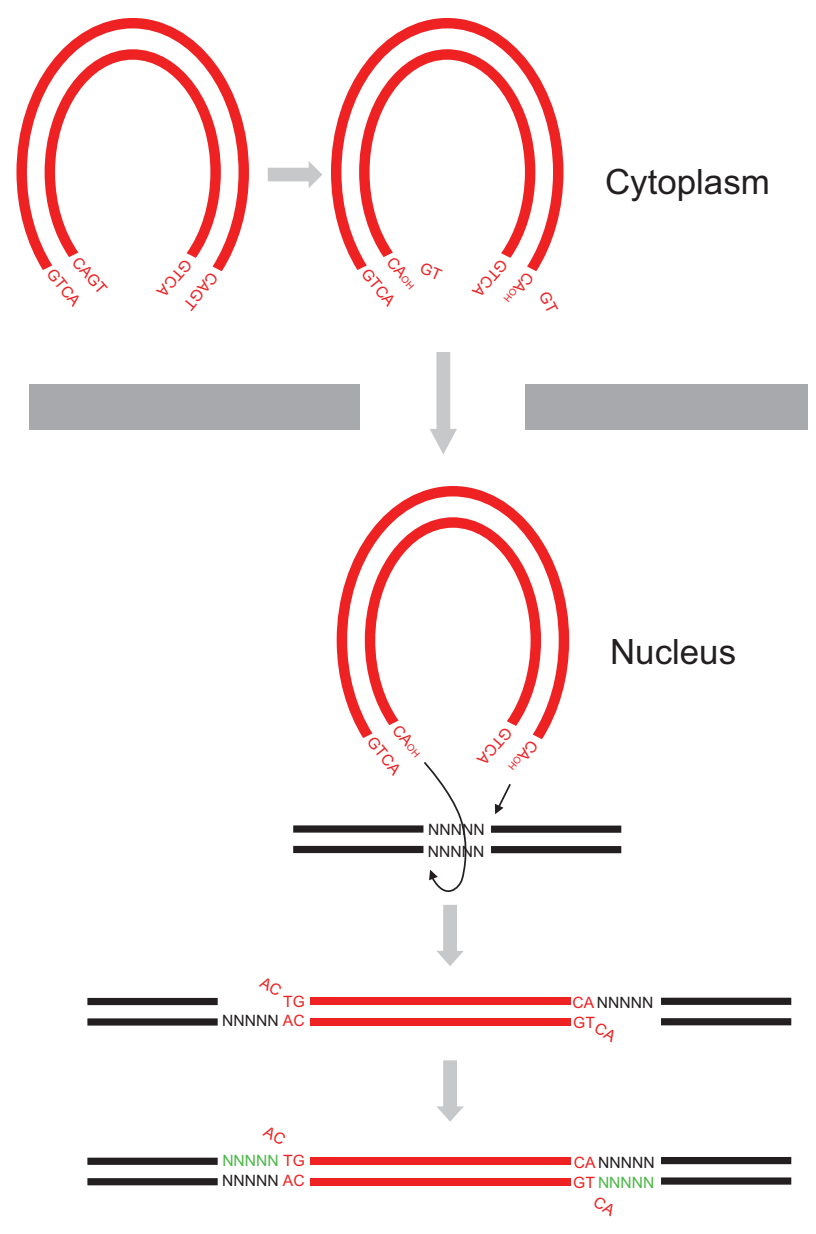

Figure I HIV-I DNA integration. HIV-I virus synthesizes a dsDNA (red) copy of its RNA genome following entry of the virus into host cell cytoplasm. HIV-I integrase removes $3^{\prime}$ end GT dinucleotides on both viral DNA ends to expose a 3 ' hydroxyl group on terminal adenosines by $3^{\prime}$ processing. The $3^{\prime}$ processed viral DNA is then imported into the nucleus where strand transfer occurs resulting in the integration of the two viral DNA ends into host DNA (black) at positions five base pairs (bp) apart. Host DNA repair enzymes then cleave unpaired viral CA dinucleotides, fill in the five bp gaps (green), and ligate the DNA ends.

DNA strands are removed, and the resulting five bp gaps on either end of the newly formed junctions are repaired and ligated. These reactions are believed to be performed by host DNA repair enzymes. ${ }^{20}$ No specific DNA sequence motif has been shown to be a preferred target for HIV-1 integration, but HIV-1 has been shown to selectively insert its DNA within transcriptional units of actively expressed host genes, whereas gamma-retroviruses, such as MLV, prefer to integrate their DNA upstream of host genes in the promoter region. ${ }^{21-24}$

IN is encoded by the C-terminal region of the HIV-1 pol gene and is a 288 amino acid-long protein that is conventionally divided into three structural and functional domains, namely N-terminal domain (NTD), catalytic core domain (CCD), and C-terminal domain (CTD). The structure of the entire HIV-1 IN has proved elusive; however, the structures of 
its three domains have been determined separately as well as two-domain fragments. ${ }^{25-27}$ These studies have revealed that the NTD encompasses IN residues 1-49 and is made up of a triplet of $\alpha$-helices, containing a double histidine/cysteine $\left(\mathrm{H}_{12}-\mathrm{H}_{16}-\mathrm{C}_{40}-\mathrm{C}_{43}\right)$ zinc-binding motif. The motif plays a role in the dimerization of IN monomers and the binding of cellular factors. ${ }^{28} \mathrm{IN}$ residues 50-212 make up the CCD which contains the IN active site composed of a triad of acidic residues D64, D116, and E152, also called the DDE motif. The motif is essential for the coordination of divalent metal ions $\left(\mathrm{Mg}^{2+}\right.$ or $\mathrm{Mn}^{2+}$ ) that are essential for IN enzymatic functions. ${ }^{28}$ The CTD, residues 213-288, contains SH3 domains that nonspecifically bind to DNA. ${ }^{29}$ It is believed that the functional entity of HIV-1 IN is a tetramer assembled from two symmetrical dimers each bound to one of the viral DNA ends. ${ }^{30}$ Elucidation of the structure of full-length HIV-1 IN and its mode of action has recently benefited from the determination of the crystal structure of prototype foamy virus (PFV) IN tetramer in complex with $3^{\prime}$ processed viral DNA ends..$^{30,31}$ This IN-DNA complex is called an intasome and is the minimal structure required for integration into target DNA. The structural model of HIV-1 intasome based on the PFV intasome shows the two viral DNA ends engaged by the active site to be $\sim 18 \AA$ apart which is equivalent to a five bp distance, thus validating the intasome as the integration functional unit. ${ }^{30}$ The intasome is also the preferred target for inhibitors of $\mathrm{IN}$, rather than the unbound enzyme, indicating a direct or indirect involvement of the viral DNA ends in inhibitor binding.

\section{Inhibitors of HIV-I IN}

To date, only one IN inhibitor has been licensed for use in HIV-1 treatment; this being raltegravir which is marketed under the brand name Isentress ${ }^{\circledR}$ (Merck \& Co., Inc., White house station, NJ) and was also formerly called MK-0518. Raltegravir, which was approved for use by the US Food and Drug Administration in 2007, is a diketo acid (DKA) analog. A signature feature of DKAs is a $\beta$-hydroxy ketone moiety (Figure 2A), and the compounds were the first molecules to be reported as potent and specific IN strand transfer inhibitors (INSTIs). The first two DKA compounds to enter clinical trials were S-1360 and L-870,810, but these agents demonstrated poor efficacy and toxicity, respectively, and were not developed further. ${ }^{32}$ However, another INSTI, namely elvitegravir, is in the late stages of clinical development and is expected to be approved for clinical use soon, with several others at different stages of development. Elvitegravir is structurally similar to quinolone antibiotics, but like raltegravir, it contains a $\beta$-hydroxy ketone moiety
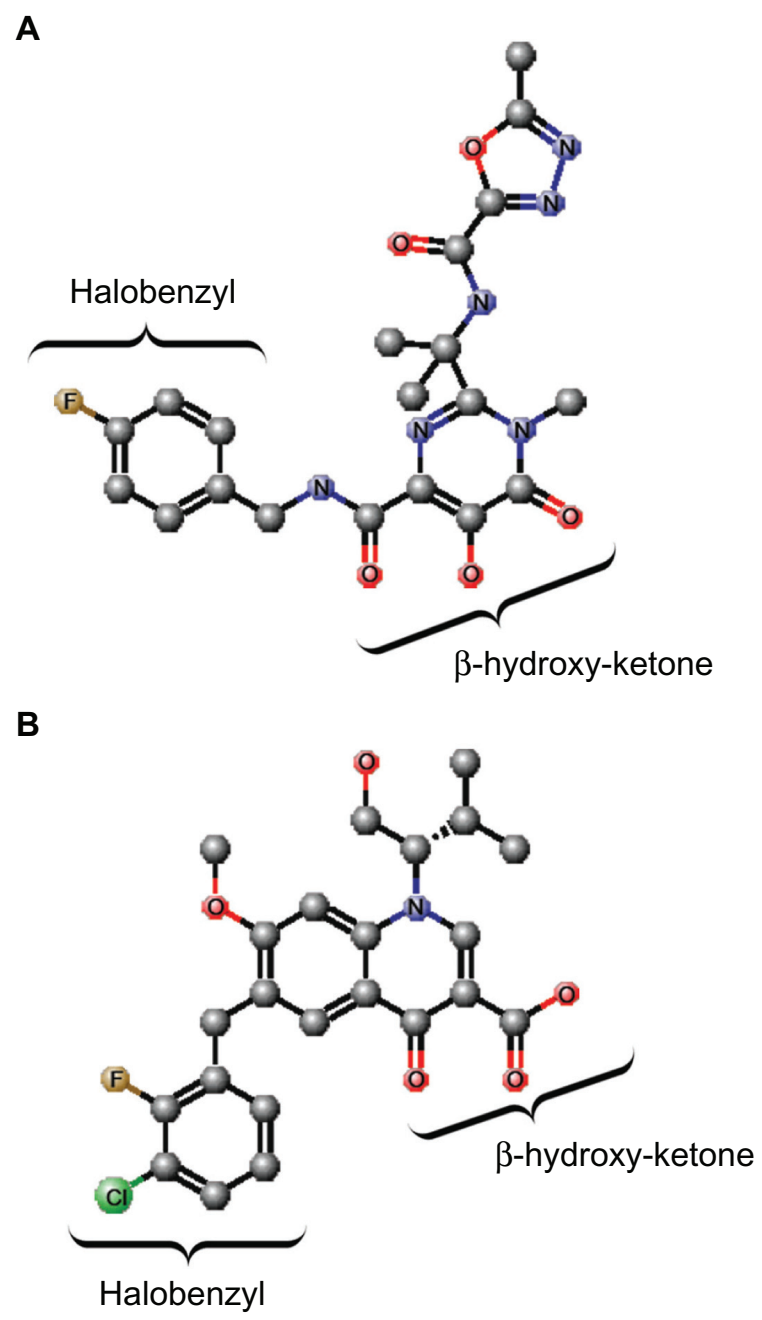

Figure 2 Structures of raltegravir and elvitegravir. A) Raltegravir. B) Elvitegravir. The $\beta$-hydroxy ketone and halobenzyl moieties are indicated. The atoms are indicated and/or represented by different colored spheres: $\mathrm{C}$, gray; $\mathrm{O}$, red; $\mathrm{N}$, blue; $\mathrm{Cl}$, green; $\mathrm{F}$, brown. Hydrogen atoms are not shown. The chemical structures were created using MarvinSketch software (ChemAxon, Budapest, Hungary).

(Figure 2B). The crystal structures of PFV in complex with the inhibitors, as well as the structural models of the HIV intasome, show that the oxygen atoms of the $\beta$-hydroxy ketone moiety chelate the divalent metal ions that are coordinated by the DDE motif of the IN active site, thereby impeding their participation in the DNA strand transfer reaction (Figure 3A, B). At the same time, the halobenzyl moieties of the inhibitors end stacked up against the cytosine of the CA dinucleotide which forces the reactive 3 ' hydroxyl group of the terminal adenosine away from the active site (Figure 3B). The drugs also make contact with residues Q146 and R231. ${ }^{30}$ In addition, raltegravir interacts with N117, Y143, N144, and P145, while elvitegravir makes only one additional contact with $\mathrm{C} 65 .^{30}$

Raltegravir and elvitegravir are very potent inhibitors of the IN strand transfer reaction with $50 \%$ inhibitory 

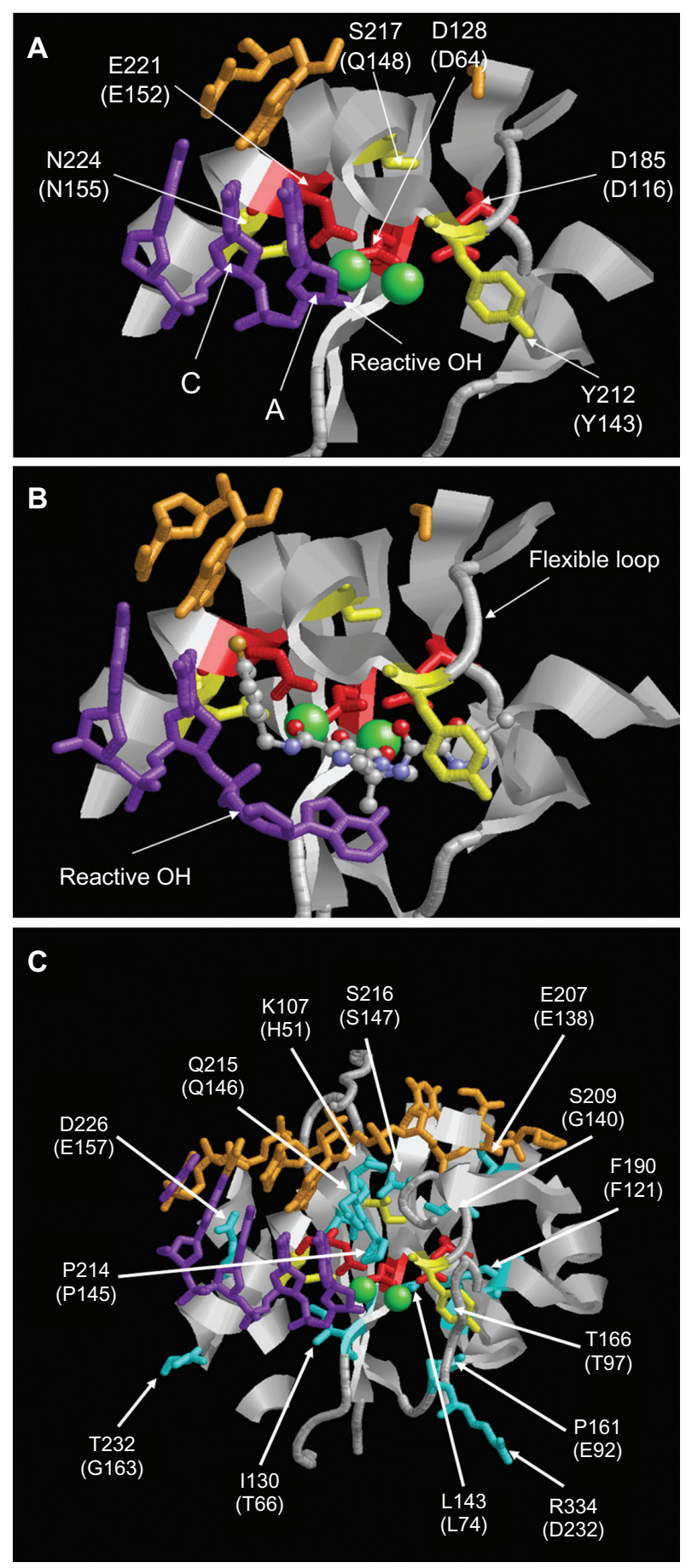

Figure 3 Structure of the PFV IN active site. A) Structure of PFV IN active site within $14 \AA$ of $\mathrm{Mn}^{2+}$ ions showing location of the three active site residues (red sticks), three residues where primary resistance mutations occur (yellow sticks), and $\mathrm{Mn}^{2+}$ ions (green spheres). B) Structure of PFV IN active site in complex with raltegravir showing the three oxygen atoms (red spheres) of the $\beta$-hydroxy ketone moiety chelating the $\mathrm{Mn}^{2+}$ ions. The halobenzyl moiety (with brown fluoride atom) is seen stacked close to the cytosine $(C)$ of the CA dinucleotide of the donor DNA strand (purple sticks) which results in the displacement of the terminal adenosine (A) and its 3' hydroxyl group from the active site. C) Structure of PFV IN active site within $20 \AA$ of $\mathrm{Mn}^{2+}$ ions showing location of some of the residues where secondary resistance mutations occur (cyan sticks). PFV residues are indicated, and the corresponding HIV-I residues are in brackets. The nontransferred DNA strand is shown as brown sticks. Protein data bank codes are $3 \mathrm{OY} 9$ and $3 \mathrm{~L} 2 \mathrm{~V},{ }^{31}$ and the diagrams were created using RasMol software (University of Massachusetts, Amherst, MA, USA). concentrations in the nanomolar range. ${ }^{33}$ Both drugs possess good safety profiles and are rarely associated with severe adverse events. A significant Achilles' heel for both drugs, as discussed in the next section, is a relatively low genetic barrier to the development of resistance such that a single mutation is enough to cause a major reduction in susceptibility. However, raltegravir and elvitegravir differ in their metabolic pathways, raltegravir being metabolized mainly by glucuronidation mediated by uridine-diphosphate-glucoronosyltransferase 1A1, whereas elvitegravir is metabolized by cytochrome P450 (CYP3A4/5) and secondarily by glucuronidation. ${ }^{34}$ As a consequence, the half-life of elvitegravir can be boosted by the coadministration of an inhibitor of CYP3A4 such as ritonavir.

\section{Resistance patterns of IN inhibitors}

Multiple mutations conferring resistance to raltegravir and elvitegravir have been described in vitro and in vivo in viruses from patients failing on raltegravir therapy. These mutations mostly involve amino acid substitutions that occur in the vicinity of the IN inhibitor-binding pocket in the CCD. ${ }^{31,32}$ Considerable cross-resistance has been demonstrated between the two inhibitors which is not surprising as structural models have shown a similar binding mechanism for raltegravir and elvitegravir at the active site of IN. ${ }^{30,31}$ Primarily, mutations causing high-level resistance to raltegravir arise independently at three residues, namely Q148 (to H, R, or K), N155 (to H), and less frequently Y143 (to C, H, or R). ${ }^{12}$ However, mutations at T66 and E92 have also been shown to significantly affect susceptibility to both drugs when present alone in vitro and in vivo, respectively. ${ }^{35,36}$ Predictably, these mutations negatively affect IN enzymatic activity, and therefore, viral replication capacity such that on the cessation of raltegravir treatment, the resistance mutations are quick to disappear, demonstrating their impact on fitness of the virus. ${ }^{37,38}$ As a consequence, the primary mutations are often accompanied by one or more specific secondary mutations that either increase resistance or restore viral fitness or both (Tables 1-3). Some of the accessory mutations, such as L74I, T97A, E138K, V151I, G163R, V165I, V201I, I203M, and T206S, are natural polymorphisms which could influence the rate of development of resistance in viruses that contain these mutations at initiation of IN inhibitor therapy. ${ }^{39-43}$ The majority of these secondary mutations are also located in the vicinity of the IN active site (Figure 3C). Interestingly, only three IN residues where drug resistance mutations occur, namely Y143, P145, and Q146, were shown to contact raltegravir and/or elvitegravir in the structural models of the 
Table I Secondary resistance mutation patterns associated with QI48HRK

\begin{tabular}{|c|c|}
\hline $\begin{array}{l}\text { Associated secondary } \\
\text { mutations }^{\mathrm{a}}\end{array}$ & $\begin{array}{l}\text { Effects on drug resistance or } \\
\text { viral fitness of Q } 148 \text { mutants }\end{array}$ \\
\hline \multicolumn{2}{|l|}{$\mathrm{NI}^{3} \mathrm{~S}^{33}$} \\
\hline \multicolumn{2}{|l|}{$\mathrm{N} I 7 \mathrm{~S}+\mathrm{GI} 63 \mathrm{R}^{33,56}$} \\
\hline $\mathrm{V} 54 \mathrm{I}+\mathrm{EI} 38 \mathrm{~K}+\mathrm{GI} 40 \mathrm{~A}^{72}$ & $\begin{array}{l}\text { Increases resistance to raltegravir } \\
\text { and elvitegravir compared to } \\
\text { addition of EI38K + GI40A; } \\
\text { increases viral fitness }\end{array}$ \\
\hline \\
\hline $\mathrm{E} I 38 \mathrm{~K}+\mathrm{V} 15 \mathrm{II}^{72}$ & \\
\hline \multicolumn{2}{|l|}{$\mathrm{L} 74 \mathrm{M}+\mathrm{GI} 40 \mathrm{~A}^{73}$} \\
\hline \multicolumn{2}{|l|}{ V79I + GI40A + GI63R ${ }^{40}$} \\
\hline \multicolumn{2}{|l|}{$E 92 Q+E I 38 K+\left.M I 54\right|^{33,56}$} \\
\hline $\mathrm{TII} 2 \mathrm{~A}+\mathrm{GI} 40 \mathrm{~S}+\mathrm{GI} 63 \mathrm{R}^{40}$ & $\begin{array}{l}\text { Increases raltegravir resistance } \\
\text { compared to addition of GI40S + } \\
\text { GI63R }\end{array}$ \\
\hline \multicolumn{2}{|l|}{$\mathrm{T} 124 \mathrm{~A}^{33,56}$} \\
\hline $\mathrm{EI} 38 \mathrm{~K} / \mathrm{A}^{33,40,42,56,72,74-76}$ & $\begin{array}{l}\text { Depending on Q } 148 \text { mutation, } \\
\text { increases resistance to raltegravir } \\
\text { and elvitegravir; increases viral } \\
\text { fitness }\end{array}$ \\
\hline$E I 38 K+G \mid 40 A^{72}$ & $\begin{array}{l}\text { Increases resistance to raltegravir } \\
\text { and elvitegravir compared } \\
\text { to addition of GI40A alone; } \\
\text { increases viral fitness }\end{array}$ \\
\hline $\mathrm{EI} 38 \mathrm{~A}+\mathrm{GI} 40 \mathrm{~S}+\mathrm{YI} 43 \mathrm{H}^{40}$ & $\begin{array}{l}\text { Increases raltegravir resistance } \\
\text { compared to addition of GI } 40 \text { S } \\
\text { alone }\end{array}$ \\
\hline$E I 38 K+G I 40 A+S 230 R^{72}$ & $\begin{array}{l}\text { Increases resistance to raltegravir } \\
\text { compared to addition of EI38K + } \\
\text { GI40A }\end{array}$ \\
\hline \multicolumn{2}{|l|}{$\mathrm{EI} 38 \mathrm{~K}+\mathrm{GI} 63 \mathrm{R}^{33,56}$} \\
\hline $\mathrm{G} \mid 40 \mathrm{~A} / \mathrm{S} / \mathrm{C}^{33,38-40,42,44,45,49,52,56,73,75-79}$ & $\begin{array}{l}\text { Depending on Q I } 48 \text { mutation, } \\
\text { increases resistance to raltegravir } \\
\text { and elvitegravir; increases viral } \\
\text { fitness }\end{array}$ \\
\hline \multicolumn{2}{|l|}{$\mathrm{GI} 40 \mathrm{~S}+\mathrm{NI} 55 \mathrm{H}^{40,77,79}$} \\
\hline \multicolumn{2}{|l|}{$\mathrm{GI} 40 \mathrm{~S}+\mathrm{K} 156 \mathrm{~N}^{73}$} \\
\hline \multicolumn{2}{|l|}{$\mathrm{GI} 40 \mathrm{~S} / \mathrm{C}+\mathrm{GI} 63 \mathrm{R} / \mathrm{K}^{33,40,45,53,56}$} \\
\hline \multicolumn{2}{|l|}{$\mathrm{GI} 40 \mathrm{~S}+\mathrm{EI} 70 \mathrm{~A}^{79}$} \\
\hline \multicolumn{2}{|l|}{$\mathrm{NI} 55 \mathrm{H}^{45,77}$} \\
\hline \multicolumn{2}{|l|}{$\mathrm{NI} 55 \mathrm{H}+\mathrm{EI}^{70 \mathrm{~A}^{79}}$} \\
\hline \multicolumn{2}{|l|}{$\mathrm{S} 147 \mathrm{G}^{77}$} \\
\hline $\mathrm{GI} 163 \mathrm{R}^{33}$ & \\
\hline
\end{tabular}

Notes: aShown are mutation patterns found in the same viral sample during in vitro or in vivo selection using raltegravir or elvitegravir. Mutations present at baseline or containing mixtures by population-based sequencing were excluded. References are given for each pattern of resistance mutations.

HIV intasome in complex with the inhibitors. ${ }^{30}$ Mutations occurring at the other sites are hypothesized to affect the conformation of the active site indirectly, so perturbing the binding of the inhibitors while preserving IN enzymatic activity. IN resistance accessory mutations have also been
Table 2 Secondary resistance mutation patterns associated with $\mathrm{NI} 55 \mathrm{H}$

\begin{tabular}{|c|c|}
\hline $\begin{array}{l}\text { Associated secondary } \\
\text { mutations }^{\mathrm{a}}\end{array}$ & $\begin{array}{l}\text { Effects on drug resistance or viral } \\
\text { fitness of N } 155 \text { mutant }\end{array}$ \\
\hline \multicolumn{2}{|l|}{$\mathrm{V} 721^{40}$} \\
\hline \multicolumn{2}{|l|}{ V72I + E92G ${ }^{40}$} \\
\hline \multicolumn{2}{|l|}{ 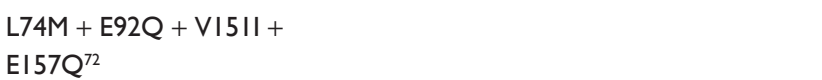 } \\
\hline $\mathrm{E} 92 \mathrm{Q} / \mathrm{A} / \mathrm{G}^{36,42,45,75-77,79}$ & $\begin{array}{l}\text { Increases raltegravir and elvitegravir } \\
\text { resistance }\end{array}$ \\
\hline$E 92 Q+T 97 A^{75}$ & $\begin{array}{l}\text { Increases raltegravir resistance } \\
\text { compared to addition of } \mathrm{E} 92 \mathrm{Q} \text { alone }\end{array}$ \\
\hline \multicolumn{2}{|l|}{$E 92 A+G 163 R^{45}$} \\
\hline Q95K ${ }^{37}$ & $\begin{array}{l}\text { Increases raltegravir and elvitegravir } \\
\text { resistance; increases viral fitness }\end{array}$ \\
\hline Q95K + VI5II37 & $\begin{array}{l}\text { Increases raltegravir and elvitegravir } \\
\text { resistance compared to addition of } \\
\text { Q95K alone }\end{array}$ \\
\hline T97A $\mathrm{A}^{40,75}$ & $\begin{array}{l}\text { Increases raltegravir and elvitegravir } \\
\text { resistance; increases viral fitness }\end{array}$ \\
\hline$T 97 A+V I 25 A+V I 5 I I^{40}$ & $\begin{array}{l}\text { Increases raltegravir resistance } \\
\text { compared to addition of VI25A }+\mathrm{VI} 151 \mathrm{I}\end{array}$ \\
\hline $\mathrm{T} 97 \mathrm{~A}+\mathrm{VI} 15 \mathrm{II} \mathrm{I}^{40,45}$ & $\begin{array}{l}\text { Increases raltegravir resistance } \\
\text { compared to addition of T79A alone }\end{array}$ \\
\hline \multicolumn{2}{|l|}{ TI24A + VI5II } \\
\hline \multicolumn{2}{|l|}{ VI25A + VI5II ${ }^{40}$} \\
\hline \multicolumn{2}{|l|}{$\mathrm{GI} 40 \mathrm{~S}^{45}$} \\
\hline \multicolumn{2}{|l|}{$\mathrm{G}|40 \mathrm{~S}+\mathrm{Q}| 48 \mathrm{H}^{40,77,79}$} \\
\hline$Y \mid 43 R / H^{40,75,77,79}$ & Increases raltegravir resistance \\
\hline \multicolumn{2}{|l|}{ YI43R + EI70A ${ }^{79}$} \\
\hline \multicolumn{2}{|l|}{ Q I 48R/H 45,77} \\
\hline \multicolumn{2}{|l|}{$\mathrm{Q} 148 \mathrm{H}+\mathrm{EI} 70 \mathrm{~A}^{79}$} \\
\hline VI5II I33,38,45,53,56,75 & Increases raltegravir resistance \\
\hline \multicolumn{2}{|l|}{$V|5 I I+M I 54|^{78}$} \\
\hline \multicolumn{2}{|l|}{ VI5II + GI63R 45,53} \\
\hline $\mathrm{GI} 63 \mathrm{R} / \mathrm{K}^{45,75,76}$ & $\begin{array}{l}\text { Increases raltegravir and elvitegravir } \\
\text { resistance; increases viral fitness }\end{array}$ \\
\hline \multicolumn{2}{|r|}{ 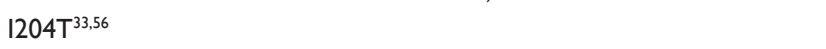 } \\
\hline $\mathrm{D} 232 \mathrm{~N}^{75}$ & \\
\hline
\end{tabular}

Notes: aShown are mutation patterns found in the same viral sample during in vitro or in vivo selection using raltegravir or elvitegravir. Mutations present at baseline or containing mixtures by population-based sequencing were excluded. References are given for each pattern of resistance mutations.

described to occur in the CTD at residue S230, suggesting a direct role for the other domains in IN enzymatic functions. Indeed, the new HIV intasome model shows that IN-viral DNA interactions not only involve residues in CCD, but also the other two domains.

\section{The Q I48R/H/K resistance pathway}

Q148 is located on the active site flexible loop, consisting of residues 140-148 which is involved in CCD-DNA contacts (Figure 3A, B). Arginine, histidine, or lysine substitutions at position 148 have been shown to reduce 
Table 3 Secondary resistance mutation patterns associated with YI43CHRK

\begin{tabular}{|c|c|}
\hline $\begin{array}{l}\text { Associated secondary } \\
\text { mutations }^{\text {a }}\end{array}$ & $\begin{array}{l}\text { Effects on drug resistance } \\
\text { or viral fitness of } \\
\text { YI43CHRK mutants }\end{array}$ \\
\hline \multicolumn{2}{|c|}{ L74M + T97A 40,53} \\
\hline \multicolumn{2}{|c|}{$\mathrm{L} 74 \mathrm{M}+\mathrm{T} 97 \mathrm{~A}+\mathrm{SI} 19 \mathrm{~T}+\mathrm{EI} 38 \mathrm{D}^{53}$} \\
\hline$L 74 M+T 97 A+E I 38 A^{40}$ & $\begin{array}{l}\text { Increases raltegravir resistance } \\
\text { compared to addition of T97A } \\
\text { alone }\end{array}$ \\
\hline \multicolumn{2}{|l|}{$L 74 M+E I 38 D^{78}$} \\
\hline $\mathrm{T}^{2} \mathrm{~A}^{40}$ & Increases raltegravir resistance \\
\hline \multicolumn{2}{|l|}{$T 97 A+E I 38 A^{40}$} \\
\hline \multicolumn{2}{|l|}{ T97A + GI40D + GI63R } \\
\hline $\mathrm{GI} 40 \mathrm{~S}^{40}$ & Increases raltegravir resistance \\
\hline \multicolumn{2}{|l|}{$\mathrm{NI} 55 \mathrm{H}^{40,77,79}$} \\
\hline $\mathrm{NI} 55 \mathrm{H}+\mathrm{EI}_{70 \mathrm{~A}^{79}}$ & \\
\hline
\end{tabular}

Notes: ${ }^{2}$ Shown are mutation patterns found in the same viral sample during in vitro or in vivo selection using raltegravir or elvitegravir. Mutations present at baseline or containing mixtures by population-based sequencing were excluded. References are given for each pattern of resistance mutations.

both the susceptibility to raltegravir and elvitegravir as well as the replication capacity of the virus..$^{42,44}$ Consequently, substitutions at Q148 often occur with the secondary mutations, such as G140S/A or E138K, which improve viral replication capacity (Table 1). These secondary mutations appear after the establishment of the codon 148 primary mutation, and the nature of the amino acid substitution at position 148 dictates the effect secondary mutations have on drug susceptibility or replication fitness. ${ }^{42,45,46}$ Fransen et al showed that on addition of G140S to a Q148R/H mutant, susceptibility to raltegravir was reduced further compared to Q148R/H alone. ${ }^{42}$ In contrast, addition of the G140S mutation to Q148K increased susceptibility to raltegravir. This study also showed that the addition of G140S improved the replication capacity of Q148H/K mutants but not Q148R. ${ }^{42}$ Another study went further to reveal that the G140S/A mutants alone impaired IN strand transfer activity without affecting the $3^{\prime}$ processing reaction. ${ }^{47}$ On the other hand, the Q148R/H/K mutants showed defective activities in both strand transfer and $3^{\prime}$ processing. Thus, it was hypothesized that substituting Q with R, H, or K (all of which have longer and bulkier side chains) alters the binding of the viral DNA to IN, therefore affecting both the strand transfer and $3^{\prime}$ processing activities. However, complementation studies have demonstrated that only the G140S/Q148H double mutant was capable of restoring IN activities to almost wild-type levels and that this complementation only operates in cis. This suggests that this double mutant is the only mutant able to restore an active site for viral DNA, allowing $3^{\prime}$ processing and strand transfer activities, while not re-establishing the raltegravir binding site. ${ }^{47}$ Hence, this may explain the evolution toward this replication efficient double mutant virus in patients failing on raltegravir treatment.

\section{The $\mathrm{N} I 55 \mathrm{H}$ resistance pathway}

The N155 residue is located on $\alpha$-helix 4 , close to active site acidic residue $\mathrm{E} 152$ involved in chelation of metal ions (Figure 3A). The mutation $\mathrm{N} 155 \mathrm{H}$ is generally associated with lower raltegravir resistance than Q148 mutations, which may explain its eventual disappearance and replacement with either the $\mathrm{Q} 148 \mathrm{R} / \mathrm{H} / \mathrm{K}$ or $\mathrm{Y} 143 \mathrm{C} / \mathrm{H} / \mathrm{R}$ mutations during raltegravir treatment failure (Figure 4) ${ }^{42,48}$ This mutant has been shown to reduce the replication capacity of the virus by impairing strand transfer activity and to some extent $3^{\prime}$ processing activity. ${ }^{37,49}$ A mechanism by which the $\mathrm{N} 155 \mathrm{H}$ mutant causes resistance to raltegravir has been reported by Grobler et al. They proposed that the N155 residue in the IN active site interacts with the residues responsible for binding the magnesium cations required for IN activity. As raltegravir binds to IN through interactions with these metal ions, mutation of this residue may prevent raltegravir from binding by disrupting the metal ion active site arrangement. ${ }^{50}$

Interestingly, studies have shown that the $\mathrm{N} 155 \mathrm{H}$ pathway has a broad range of reductions in raltegravir susceptibility which is dependent on the type of secondary mutations that have also been accumulated (Table 2). However, it has been suggested that the 155 pathway does not confer a stable state of raltegravir resistance regardless of the accumulated secondary mutations since the type of secondary mutations in a viral population containing the $\mathrm{N} 155 \mathrm{H}$ primary mutation vary greatly over time. ${ }^{45}$ Among the INSTI resistance-associated secondary mutations, the E92Q mutation has been shown to preferentially occur with the $\mathrm{N} 155 \mathrm{H}$ mutation by clonal analysis and also that the addition of the E92Q mutation to $\mathrm{N} 155 \mathrm{H}$ results in further decreases in both replication capacity and raltegravir susceptibility. ${ }^{42}$ It was thus hypothesized that selection of E92Q after the

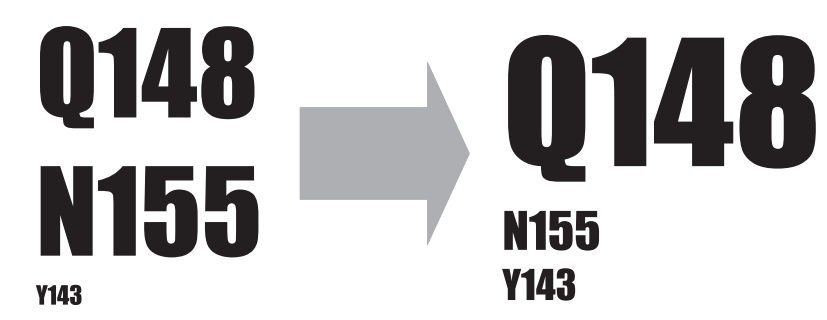

Figure 4 Schematic representation of the evolution of raltegravir primary resistance mutations. Initially, mutations conferring resistance to raltegravir have been shown to primarily occur at residues Q 148 and NI55. Subsequently, switches from I48 or I 55 pathways to 148 or 143 pathways have been observed. 
establishment of $\mathrm{N} 155 \mathrm{H}$ in the virus is probably driven by the increase in raltegravir resistance rather than to compensate for replication capacity. ${ }^{42}$ However, a recent study by Fun and colleagues has shown that subsequent selection of the Q95K mutation by the N155H-containing virus resulted in increased raltegravir resistance as well as a partially restored replication capacity. ${ }^{37}$ Further addition of the V151I mutation resulted in reduction in replication capacity but an additional increase in raltegravir resistance, generating a virus with an overall higher level of fitness in the presence of raltegravir. Indeed, this triple mutant virus was shown to rapidly dominate the viral population in one patient during raltegravir treatment failure. ${ }^{37}$

\section{The $Y$ I 43C/H/R resistance pathway}

Similar to Q148, Y143 is located on the active site flexible loop (Figure 3A, B). As mentioned earlier, residue Y143 is one of a few residues that directly make contact with raltegravir when the inhibitor is bound at the active site. ${ }^{30}$ Therefore, development of IN inhibitor resistance via mutation of Y143 can be explained by a direct effect on inhibitor binding. As with the other resistance pathways, mutations at position 143 in the viral IN gene have been shown to increase resistance to raltegravir while reducing the replication capacity of the virus. ${ }^{40,48,51}$ The level of raltegravir resistance associated with this pathway, however, is believed to be higher than that of the Q148H/G140S double mutant and other primary mutations. ${ }^{51}$ In vitro studies show that the Y143R/C mutants have impaired $3^{\prime}$ processing and strand transfer activities. The $3^{\prime}$ processing activity was more affected in the R mutant than the $\mathrm{C}$ mutant, whereas the strand transfer activity was more efficient in the R mutant. Regardless, both mutants had similar levels of resistance to raltegravir leading the authors to conclude that perhaps the Y143C mutant was a transient form of the $\mathrm{Y} 143 \mathrm{R}$ mutant, as a $\mathrm{Y}$ to $\mathrm{C}$ change involves a single bp change, whereas a $\mathrm{Y}$ to $\mathrm{R}$ change requires two bp changes. Structural modeling analysis of the Y143R/C mutants suggested that these mutants may allow for an alternative recognition site for DNA binding, in particular, the post-3' processing contact with the 5'AC overhang, while preventing the binding of raltegravir to the enzyme. ${ }^{51}$ In another study by Reigadas et al, the strand transfer activity of the Y143R/C mutants was shown to be severely impaired, but the $3^{\prime}$ processing activity was only moderately impaired. They showed that this mutant was highly resistant to raltegravir but had a much lower replication capacity than wildtype virus. Drawing on conclusions from unpublished data from Fransen et al, ${ }^{42}$ Reigadas and colleagues suggested that perhaps the protease and/or reverse transcriptase of the virus help to rescue this replication capacity deficit. ${ }^{48}$ Studies have shown that Y143R/C mutants can be present either alone or in association with other secondary mutations (Table 3). Little is yet known about the effects of these secondary mutations on the raltegravir resistance levels and replication capacity of the viruses expressing the Y143R/C mutations. Nonetheless, it is widely considered that these mutations play a positive role in IN activity and/or resistance to raltegravir. ${ }^{40,48,51}$

Several other IN resistance mutation patterns have been described that do not involve mutations at Y143, Q148, or N155 (Table 4). However, the three main resistance pathways described above have been shown to be mutually exclusive. Several studies have shown that the different pathways can be

Table 4 Other integrase resistance mutation patterns

\begin{tabular}{|c|c|}
\hline $\begin{array}{l}\text { Other resistance } \\
\text { mutation patterns }^{\mathrm{a}}\end{array}$ & $\begin{array}{l}\text { Effects on drug resistance } \\
\text { or viral fitness }\end{array}$ \\
\hline $\mathrm{H} 5 \mathrm{IY}+\mathrm{E} 92 \mathrm{Q}+\mathrm{SI} 47 \mathrm{G}^{35}$ & $\begin{array}{l}\text { Increased resistance to elvitegravir } \\
\text { compared to } \mathrm{E} 92 \mathrm{Q} \text { alone }\end{array}$ \\
\hline \multicolumn{2}{|l|}{$\mathrm{G} 9 \mathrm{E}^{33}$} \\
\hline $\mathrm{T} 661 / \mathrm{A} / \mathrm{K}^{33,56,74,80}$ & $\begin{array}{l}\text { Resistance to elvitegravir; resistance } \\
\text { to raltegravir depending on mutation }\end{array}$ \\
\hline$T 66 I+V 72 A+A I 28 T^{33,56}$ & Resistance to elvitegravir \\
\hline \multicolumn{2}{|l|}{$\mathrm{T} 66 \mathrm{~A}+\mathrm{L} 74 \mathrm{I}+\mathrm{E} 92 \mathrm{Q}^{52}$} \\
\hline$T 66 I+E 92 Q+T I 24 A^{33,56}$ & Resistance to elvitegravir \\
\hline $\begin{array}{l}\text { T66I + Q95K + EI38K + } \\
\text { QI46P + SI47G } 35\end{array}$ & $\begin{array}{l}\text { Increased resistance to elvitegravir } \\
\text { compared to addition of T66I + } \\
\text { QI46P + SI47G }\end{array}$ \\
\hline$T 661 / K+T I 24 A^{33,56}$ & Resistance to elvitegravir \\
\hline$T 661+T I 24 A+Q 146 L^{33,56}$ & Resistance to elvitegravir \\
\hline $\mathrm{T} 661+\mathrm{Q} 146 \mathrm{P}^{35}$ & $\begin{array}{l}\text { Increased resistance to elvitegravir } \\
\text { compared to T66I or Q } 146 \mathrm{P} \text { alone }\end{array}$ \\
\hline $\mathrm{T} 661+\mathrm{Q} 146 \mathrm{P}+\mathrm{SI} 47 \mathrm{G}^{35}$ & $\begin{array}{l}\text { Increased resistance to elvitegravir } \\
\text { compared to addition of T66I + Q I 46P }\end{array}$ \\
\hline $\mathrm{T} 66 \mathrm{I}+\mathrm{S} 230 \mathrm{R}^{74}$ & Resistance to elvitegravir \\
\hline $\mathrm{L} 68 \mathrm{~V} / \mathrm{I}+\mathrm{E} 92 \mathrm{Q}^{36}$ & $\begin{array}{l}\text { Increased resistance to elvitegravir and } \\
\text { raltegravir compared to } \mathrm{E} 92 \mathrm{Q} \text { alone }\end{array}$ \\
\hline $\mathrm{E} \mathrm{QQ}^{33,35,42,49,56,74,80}$ & Resistance to elvitegravir \\
\hline $\mathrm{E} 92 \mathrm{QV}+\mathrm{TI} 24 \mathrm{~A}^{33,56}$ & Resistance to elvitegravir \\
\hline $\mathrm{E} 92 \mathrm{Q}+\left.\mathrm{MI} 54\right|^{33}$ & Resistance to raltegravir \\
\hline TI24A 33,56 & $\begin{array}{l}\text { No resistance to raltegravir or } \\
\text { elvitegravir }\end{array}$ \\
\hline $\mathrm{TI} 24 \mathrm{~A}+\mathrm{PI} 45 \mathrm{~S}^{33,56}$ & Resistance to elvitegravir \\
\hline $\mathrm{T} I 24 \mathrm{~A}+\mathrm{Q} \mid 46 \mathrm{~L}^{33,56}$ & Resistance to elvitegravir \\
\hline $\mathrm{PI} 45 \mathrm{~S}^{33,56,81}$ & Resistance to elvitegravir \\
\hline $\mathrm{Q} 146 \mathrm{P}+\mathrm{N} 232 \mathrm{D}^{35}$ & Resistance to elvitegravir \\
\hline VI5II & Resistance to elvitegravir \\
\hline \multicolumn{2}{|l|}{$\mathrm{E} 57 \mathrm{Q}^{49}$} \\
\hline $\mathrm{S} 230 \mathrm{~N} / \mathrm{R}^{73,74}$ & $\begin{array}{l}\text { No effect on raltegravir or elvitegravir } \\
\text { resistance }\end{array}$ \\
\hline
\end{tabular}

Notes: aShown are mutation patterns found in the same viral sample during in vitro or in vivo selection using raltegravir or elvitegravir. Mutations present at baseline or containing mixtures by population-based sequencing were excluded. References are given for each pattern of resistance mutations. 
present in the same viral population within patients undergoing virological failure albeit on different genomes. ${ }^{38,42,45,48,52}$ This suggests that a virus containing more than one of the primary mutations is probably severely impaired and replicatively compromised. Nonetheless, it has been suggested that the evolution of raltegravir resistance mutations is mostly driven by the need to increase levels of resistance during drugselective pressure rather than replication fitness. ${ }^{40,42}$ Indeed, a switch from the 155 to the 148 pathway is often observed during treatment failure (Figure 4) and is believed possibly to be linked to higher levels of raltegravir resistance seen with the 148 pathway. ${ }^{45}$ Switches from either the 148 or 155 pathways to the 143 pathway have also been observed during treatment failure. ${ }^{40,48,53}$ However, in this case, it is believed that the eventual emergence of the 143 pathway may be associated with its replicative advantage in the presence of raltegravir rather than an increase in resistance levels. ${ }^{44}$

Two second-generation INSTIs are in late stages of development by GlaxoSmithKline (GSK) and Shionogi, namely S/GSK1349572 and S/GSK1265744. ${ }^{54}$ Of interest, the pattern of resistance mutations associated with S/GSK1349572 in cell culture passages was shown to be different from that seen with raltegravir or elvitegravir. Resistance mutation patterns associated with S/GSK1349572 included T124A, S153Y, T124A/S153Y, T124A/S153F, and L101I/T124A/ S153Y. S/GSK1349572 has been shown to either completely or partially inhibit raltegravir- and elvitegravir-resistant viruses in vitro. ${ }^{55-57}$ However, combination mutations involving primary mutations at Q148 and N155 have been shown to still cause a significant loss of activity although less than that observed with raltegravir. This suggests that these compounds have a similar mode of action to raltegravir and elvitegravir.

\section{Use of raltegravir in clinical practice}

Initially, raltegravir was approved for use in patients who had experienced treatment failure on previous regimens; however, it is now being considered for use in first-line regimens. ${ }^{58}$ Several studies have looked at the effectiveness of raltegravir in treatment-experienced and treatment-naïve patients.

\section{Treatment-experienced patients}

The BENCHMRK trial showed that raltegravir was highly effective in the treatment of patients when combined with an optimized background regimen. A total of $57 \%$ of patients receiving raltegravir had undetectable viral load (VL) $(<50$ RNA copies/mL) at 96 weeks, compared with $26 \%$ of placebo recipients who only received optimized therapy. The best results were seen when raltegravir was combined with two new active agents. ${ }^{59}$ Significantly, greater rises in CD4 counts were also seen in the raltegravir recipients. Thus, overall, these studies showed that raltegravir could contribute to long-term viral suppression in patients with multidrug-resistant HIV, provided that other drugs in the regimen were also effective.

\section{Treatment-naïve patients}

Raltegravir has been shown to be noninferior to efavirenz when combined with tenofovir and emtricitabine in the STARTMRK trial and was associated with faster virological responses. ${ }^{60}$ There have also been studies to examine the effectiveness of NRTI-sparing combinations where raltegravir has been used with ritonavir-boosted lopinavir or unboosted atazanavir. The first showed similar outcomes to use of raltegravir with tenofovir and emtricitabine, ${ }^{61}$ whereas the latter was discontinued due to adverse effects and a higher number of virological failures. ${ }^{62}$ Thus, the combination of raltegravir with tenofovir and emtricitabine is now regarded as a useful possible alternative first-line therapy, although long-term experience with potential toxicities due to raltegravir have yet to be determined. ${ }^{63}$ A coformulation pill known as Quad, comprising of elvitegravir with a novel pharmacoenhancer called cobicistat (GS-9350) plus emtricitabine and tenofovir, is also undergoing clinical trials in ART-naïve HIV-infected individuals. In phase II trials, Quad has been shown to have similar efficacy and to be associated with less adverse effects compared to Atripla (efavirenz + emtricitabine + tenofovir). ${ }^{64}$

\section{Switching therapies}

Two trials, SWITCHMRK and SPIRAL, have looked at replacing PIs with raltegravir in suppressed patients, but only in SPIRAL was the raltegravir switch found to be noninferior. ${ }^{65,66}$ The reasons for the different outcomes are believed to lie in the previous treatment histories of the patients and whether they had experienced virological failure before.

\section{Future research and optimal use of existing and emerging agents}

The development of HIV-1 IN inhibitors has been ongoing for nearly two decades, but success has been long time coming, in terms of drugs approved for clinical use, with only raltegravir licensed for clinical use to date. In part, this is because the knowledge of how IN inhibitors work and the mechanism of IN drug resistance has been incomplete due to 
the lack of a crystal structure of HIV-1 IN alone or in complex with inhibitors. The recent elucidation of the structure of the PFV intasome in complex with first-generation INSTIs has helped produce better structural models of the HIV-1 intasome-INSTI complex..$^{30,31}$ This is a significant event that will advance the strategic design and development of new active site inhibitors against both wild-type IN and drug-resistant IN mutants or spur improvements of existing INSTIs. Despite the close relation of PFV and HIV-1 IN proteins, structural differences do exist between the two, such as the presence of the N-terminal extension domain in PFV, which is involved in nonspecific DNA binding of viral DNA ends. ${ }^{31}$ Therefore, HIV IN drug design will benefit even more from the elucidation of a crystal structure of HIV-1 IN in complex with inhibitors, and that still remains a major goal for IN inhibitor drug design and development.

In addition to understanding the mechanism of inhibition and drug resistance profiles of available INSTIs, an HIV-1 intasome model or crystal structure will enable the development of inhibitors that can target other IN regions apart from the active site, akin to the development of RTIs. Zidovudine was the first RTI developed as a competitive nucleoside analog inhibitor that blocked HIV-1 DNA synthesis by binding at the polymerase active site. ${ }^{4}$ Following its discovery, structural modeling played a prominent role in the design and development of non-nucleoside inhibitors that bound outside the polymerase active site. ${ }^{5}$ This new class of inhibitors blocked HIV-1 DNA synthesis by affecting the conformation of the active site, a feat better understood with the help of structural models. ${ }^{5}$ As mentioned earlier, the discovery of this new class of ARVs prompted the use of combination therapy as the resistance mutation profiles for the two classes are mutually exclusive. It is, therefore, envisaged that understanding the structure of the HIV-1 intasome could fuel the search for agents that inhibit HIV-1 integration by binding outside of the IN active site and/or by a different mechanism, which can then be used in combination with first-generation INSTIs, raltegravir or elvitegravir.

With that goal in mind, several avenues for the discovery of IN inhibitors are already being explored and could produce future drugs in addition to the first- and second-generation INSTIs. ${ }^{32}$ Other reactions or interactions involving IN, apart from the strand transfer reaction, could provide potential targets for blocking HIV-1 integration. These include the $3^{\prime}$ processing reaction, the interaction of IN with both viral and target DNA, the dimerization or oligomerization of IN, and the interaction of IN with host or viral cofactors. Several such agents have been discovered in the past few years, but some of these have not been developed further partly due to a lack of an understanding of their mechanism of action. Structural models of these inhibitors in complex with an HIV-1 intasome can lead to improvements in their design and alternative means of inhibiting HIV-1 DNA integration.

The holy grail for HIV therapy is the complete eradication of the virus in infected individuals; however, this still remains elusive. Studies on viral eradication have shown that the reduction of VL in infected individuals during effective HAART occurs rapidly during the early phases. However, the later phase involves a further gradual and long-term reduction in VL with estimates of more than 60 years for complete eradication of the virus from the infected individual to occur. ${ }^{67,68}$ It is believed that the latency of HIV-1 infection and probably the persistent low-level expression of nascent virions from long-lived cells infected prior to commencement of HAART could be significant bottlenecks to achieving eradication. One strategy, which has been attempted, is ARV treatment intensification with or without the use of selective inducers of HIV-1 expression. Raltegravir has been one of the ARVs chosen for intensification therapy partially because it has been documented to produce an accelerated decay of HIV-1 RNA in infected individuals. This is believed to result from improved distribution of raltegravir to less accessible sites and cells capable of producing HIV-1 particles, such as in the cerebrospinal fluid. ${ }^{69}$ However, preliminary results have proved disappointing with unsustainable reductions of residual HIV-1 viremia and no eradication of the virus. ${ }^{70,71}$ In the future, intensification treatments could involve the use of raltegravir or novel IN inhibitors with or without more potent inducers of HIV-1 expression. Other areas of raltegravir use being investigated include prevention of perinatal infection and postexposure prophylaxis.

\section{Conclusions}

The pattern of development of resistance to INSTIs has been extensively investigated. Three primary mutations occurring independently at residues Q148, N155, and Y143 result in high-level resistance to first-generation INSTIs. These mutations are often accompanied by other mutations in IN which increase resistance and/or improve replication capacity of the virus. Multiple cell-based and biochemical assays have been used to understand the effects of the mutations associated with resistance to INSTIs. The recent availability of the structural model of an HIV-1 intasome that has been obtained following the elucidation of the crystal structure of the PFV intasome has significantly augmented the understanding of the mechanisms of resistance to INSTIs. The availability 
of the HIV-1 intasome structural model will undoubtedly bolster the strategic design of new inhibitors and will help predict how HIV-1 might evolve resistance to the drugs. The structural model could also allow improvements to be made to existing IN inhibitors with the goal of reducing the chances for the development of resistance.

The increase in the classes and numbers of ARVs, which now includes IN inhibitors, has significantly contributed to the success of HAART. This has allowed the complete suppression of viral replication in infected individuals, resulting in undetectable HIV-1 RNA levels of $<50$ copies/mL. This can be achieved not only in ART-naïve individuals, but also in individuals who have experienced treatment failure on previous regimens. An understanding of the evolution of drug resistance in the new classes of ARVs is crucial to maintaining or improving on this success as well as in the design of next generation drugs in these new classes.

\section{Disclosure}

The authors report no conflicts of interest in this work.

\section{References}

1. Broder $\mathrm{S}$. The development of antiretroviral therapy and its impact on the HIV-1/AIDS pandemic. Antiviral Res. 2010;85(1):1-18.

2. Palella FJ Jr, Delaney KM, Moorman AC, et al. Declining morbidity and mortality among patients with advanced human immunodeficiency virus infection. HIV Outpatient Study Investigators. $N$ Engl J Med. 1998;338(13):853-860.

3. Walensky RP, Paltiel AD, Losina E, et al. The survival benefits of AIDS treatment in the United States. J Infect Dis. 2006;194(1):11-19.

4. Cihlar T, Ray AS. Nucleoside and nucleotide HIV reverse transcriptase inhibitors: 25 years after zidovudine. Antiviral Res. 2010;85(1):39-58.

5. De Bethune MP. Non-nucleoside reverse transcriptase inhibitors (NNRTIs), their discovery, development, and use in the treatment of HIV-1 infection: a review of the last 20 years (1989-2009). Antiviral Res. 2010;85(1):75-90.

6. Wensing AM, van Maarseveen NM, Nijhuis M. Fifteen years of HIV protease inhibitors: raising the barrier to resistance. Antiviral Res. 2010;85(1):59-74.

7. Craigie R. HIV integrase, a brief overview from chemistry to therapeutics. J Biol Chem. 2001;276(26):23213-23216.

8. Engelman A. Reverse transcription and integration. In: Kurth A, Bannert N, editors. Retroviruses: Molecular Biology, Genomics and Pathogenesis. Norfolk (UK): Caister Academic Press; 2010:129-159.

9. Hazuda DJ, Felock P, Witmer M, et al. Inhibitors of strand transfer that prevent integration and inhibit HIV-1 replication in cells. Science. 2000;287(5453):646-650.

10. Pommier Y, Johnson AA, Marchand C. Integrase inhibitors to treat HIV/AIDS. Nat Rev Drug Discov. 2005;4(3):236-248.

11. Markowitz M, Nguyen BY, Gotuzzo E, et al; Protocol 004 Part II Study Team. Rapid and durable antiretroviral effect of the HIV-1 integrase inhibitor raltegravir as part of combination therapy in treatment-naïve patients with HIV-1 infection: results of a 48-week controlled study. J Acquir Immune Defic Syndr. 2007;46(2):125-133.

12. Cooper DA, Steigbigel RT, Gatell JM, et al; BENCHMRK Study Teams. Subgroup and resistance analyses of raltegravir for resistant HIV-1 infection. N Engl J Med. 2008;359(4):355-365.
13. Steigbigel RT, Cooper DA, Kumar PN, et al; BENCHMRK Study Teams. Raltegravir with optimized background therapy for resistant HIV-1 infection. N Engl J Med. 2008;359(4):339-354.

14. Bukrinsky MI, Sharova N, McDonald TL, Pushkarskaya T, Tarpley WG, Stevenson M. Association of integrase, matrix, and reverse transcriptase antigens of human immunodeficiency virus type 1 with viral nucleic acids following acute infection. Proc Natl Acad Sci U SA. 1993;90(13): 6125-6129.

15. Miller MD, Farnet CM, Bushman FD. Human immunodeficiency virus type 1 preintegration complexes: studies of organization and composition. J Virol. 1997;71(7):5382-5390.

16. Bushman FD. Host proteins in retroviral cDNA integration. Adv Virus Res. 1999;52:301-317.

17. Lin CW, Engelman A. The barrier-to-autointegration factor is a component of functional human immunodeficiency virus type 1 preintegration complexes. J Virol. 2003;77(8):5030-5036.

18. Raghavendra NK, Shkriabai N, Graham RLJ, Hess S, Kvaratskhelia M, Wu L. Identification of host proteins associated with HIV-1 preintegration complexes isolated from infected CD4+ cells. Retrovirology. 2010;7:66.

19. Woodward CL, Prakobwanakit S, Mosessian S, Chow SA. Integrase interacts with nucleoporin NUP153 to mediate the nuclear import of human immunodeficiency virus type 1. J Virol. 2009;83(13):6522-6533.

20. Yoder KE, Bushman FD. Repair of gaps in retroviral DNA integration intermediates. J Virol. 2000;74(23):11191-11200.

21. Schroder AR, Shinn P, Chen H, Berry C, Ecker JR, Bushman F. HIV-1 integration in the human genome favors active genes and local hotspots. Cell. 2002;110(4):521-529.

22. Mitchell RS, Beitzel BF, Schroder AR, et al. Retroviral DNA integration: ASLV, HIV, and MLV show distinct target site preferences. PLoS Biol. 2004;2(8):E234.

23. Wu X, Burgess SM. Integration target site selection for retroviruses and transposable elements. Cell Mol Life Sci. 2004;61(19-20): 2588-2596.

24. Maxfield LF, Fraize CD, Coffin JM. Relationship between retroviral DNA-integration-site selection and host cell transcription. Proc Natl Acad Sci U S A. 2005;102(5):1436-1441.

25. Dyda F, Hickman AB, Jenkins TM, Engelman A, Craigie R, Davies DR. Crystal structure of the catalytic domain of HIV-1 integrase: similarity to other polynucleotidyl transferases. Science. 1994;266(5193): 1981-1986.

26. Chen JC, Krucinski J, Miercke LJ, et al. Crystal structure of the HIV-1 integrase catalytic core and C-terminal domains: a model for viral DNA binding. Proc Natl Acad Sci U S A. 2000;97(15):8233-8238.

27. Wang JY, Ling H, Yang W, Craigie R. Structure of a two-domain fragment of HIV-1 integrase: implications for domain organization in the intact protein. EMBO J. 2001;20(24):7333-7343.

28. McColl DJ, Chen X. Strand transfer inhibitors of HIV-1 integrase: bringing IN a new era of antiretroviral therapy. Antiviral Res. 2010;85(1): 101-118.

29. Engelman A, Hickman AB, Craigie R. The core and carboxyl-terminal domains of the integrase protein of human immunodeficiency virus type 1 each contribute to nonspecific DNA binding. JVirol. 1994;68(9): 5911-5917.

30. Krishnan L, Li X, Naraharisetty HL, Hare S, Cherepanov P, Engelman A. Structure-based modeling of the functional HIV-1 intasome and its inhibition. Proc Natl Acad Sci U S A. 2010;107(36): $15910-15915$.

31. Hare S, Gupta SS, Valkov E, Engelman A, Cherepanov P. Retroviral intasome assembly and inhibition of DNA strand transfer. Nature. 2010;464(7286):232-236.

32. Marchand C, Maddali K, Metifiot M, Pommier Y. HIV-1 IN inhibitors: 2010 update and perspectives. Curr Top Med Chem. 2009;9(11): 1016-1037.

33. Kobayashi M, Nakahara K, Seki T, et al. Selection of diverse and clinically relevant integrase inhibitor-resistant human immunodeficiency virus type 1 mutants. Antiviral Res. 2008;80(2):213-222. 
34. Pace P, Rowley M. Integrase inhibitors for the treatment of HIV infection. Curr Opin Drug Discov Devel. 2008;11(4):471-479.

35. Shimura K, Kodama E, Sakagami Y, et al. Broad antiretroviral activity and resistance profile of the novel human immunodeficiency virus integrase inhibitor elvitegravir (JTK-303/GS-9137). JVirol. 2008;82(2): 764-774.

36. Goodman D, Hluhanich R, Waters J, et al. Integrase inhibitor resistance involves complex interactions among primary and secondary resistance mutations: a novel mutation L68V/I associates with E92Q and increases resistance [abstract]. Antivir Ther. 2008;13 Suppl 3:A15.

37. Fun A, van Baelen K, van Lelyveld SF, et al. Mutation Q95K enhances $\mathrm{N} 155 \mathrm{H}$-mediated integrase inhibitor resistance and improves viral replication capacity. J Antimicrob Chemother. 2010;65(11): 2300-2304.

38. Ferns RB, Kirk S, Bennett J, Williams I, Edwards S, Pillay D. The dynamics of appearance and disappearance of HIV-1 integrase mutations during and after withdrawal of raltegravir therapy. AIDS. 2009; 23(16):2159-2164.

39. Ceccherini-Silberstein F, Armenia D, D'Arrigo R, et al. Virological response and resistance in multi-experienced patients treated with raltegravir [abstract]. Antivir Ther. 2008;13 Suppl 3:A20.

40. Canducci F, Marinozzi MC, Sampaolo M, et al. Genotypic/phenotypic patterns of HIV-1 integrase resistance to raltegravir. $J$ Antimicrob Chemother. 2010;65(3):425-433.

41. Myers RE, Pillay D. Analysis of natural sequence variation and covariation in human immunodeficiency virus type 1 integrase. J Virol. 2008; 82(18):9228-9235.

42. Fransen S, Gupta S, Danovich R, et al. Loss of raltegravir susceptibility by human immunodeficiency virus type 1 is conferred via multiple nonoverlapping genetic pathways. J Virol. 2009;83(22):11440-11446.

43. Rhee SY, Liu TF, Kiuchi M, et al. Natural variation of HIV-1 group M integrase: implications for a new class of antiretroviral inhibitors. Retrovirology. 2008;5:74.

44. Delelis O, Malet I, Na L, et al. The G140S mutation in HIV integrases from raltegravir-resistant patients rescues catalytic defect due to the resistance Q148H mutation. Nucleic Acids Res. 2009;37(4): 1193-1201.

45. Malet I, Delelis O, Soulie C, et al. Quasispecies variant dynamics during emergence of resistance to raltegravir in HIV-1-infected patients. J Antimicrob Chemother. 2009;63(4):795-804.

46. Nakahara K, Wakasa-Morimoto C, Kobayashi M, et al. Secondary mutations in viruses resistant to HIV-1 integrase inhibitors that restore viral infectivity and replication kinetics. Antiviral Res. 2009; 81(2):141-146.

47. Metifiot M, Maddali K, Naumova A, Zhang X, Marchand C, Pommier Y. Biochemical and pharmacological analyses of HIV-1 integrase flexible loop mutants resistant to raltegravir. Biochemistry. 2010;49(17):3715-3722

48. Reigadas S, Anies G, Masquelier B, et al. The HIV-1 integrase mutations $\mathrm{Y} 143 \mathrm{C} / \mathrm{R}$ are an alternative pathway for resistance to raltegravir and impact the enzyme functions. PLoS One. 2010;5(4):e10311.

49. Malet I, Delelis O, Valantin MA, et al. Mutations associated with failure of raltegravir treatment affect integrase sensitivity to the inhibitor in vitro. Antimicrob Agents Chemother. 2008;52(4):1351-1358.

50. Grobler JA, Stillmock KA, Miller MD, Hazuda DJ. Mechanism by which the HIV integrase active-site mutation $\mathrm{N} 155 \mathrm{H}$ confers resistance to raltegravir [abstract]. Antivir Ther. 2008;13 Suppl 3:A41.

51. Delelis O, Thierry S, Subra F, et al. Impact of Y143 HIV-1 integrase mutations on resistance to raltegravir in vitro and in vivo. Antimicrob Agents Chemother. 2010;54(1):491-501.

52. Charpentier C, Karmochkine M, Laureillard D, et al. Drug resistance profiles for the HIV integrase gene in patients failing raltegravir salvage therapy. HIV Med. 2008;9(9):765-770.

53. Sichtig N, Sierra S, Kaiser R, et al. Evolution of raltegravir resistance during therapy. J Antimicrob Chemother. 2009;64(1):25-32.

54. Prada N, Markowitz M. Novel integrase inhibitors for HIV. Expert Opin Investig Drugs. 2010;19(9):1087-1098.
55. Underwood M, Johns B, Sato A, Fujiwara T, Spreen W. S/GSK1349572: a next generation integrase inhibitor with activity against integrase inhibitor-resistant clinical isolates from patients experiencing virologic failure while on raltegravir therapy [abstract]. 5th IAS Conference on HIV Pathogenesis, Treatment and Prevention; 2009 Jul 19-22; Cape Town, South Africa.

56. Sato A, Kobayashi M, Yoshinaga T, et al. S/GSK1349572 is a potent next generation HIV integrase inhibitor [abstract]. 5th IAS Conference on HIV Pathogenesis, Treatment and Prevention; 2009 Jul 19-22; Cape Town, South Africa.

57. Seki T, Kobayashi M, Wakasa-Morimoto C, et al. S/GSK1349572 is a potent next generation HIV integrase inhibitor and demonstrates a superior resistance profile substantiated with 60 integrase mutant molecular clones [abstract]. 17th Conference on Retroviruses and Opportunistic Infections; 2010 Feb 16-19; San Francisco, CA.

58. World Health Organization (WHO). Antiretroviral therapy for HIV infection in adults and adolescents: recommendations for a public health approach. 2010. Available from: http://whqlibdoc.who.int/ publications/2010/9789241599764_eng.pdf. Accessed January 13, 2011.

59. Steigbigel RT, Cooper DA, Teppler H, et al; BENCHMRK Study Teams. Long-term efficacy and safety of raltegravir combined with optimized background therapy in treatment-experienced patients with drug-resistant HIV infection: week 96 results of the BENCHMRK 1 and 2 Phase III trials. Clin Infect Dis. 2010;50(4):605-612.

60. Lennox JL, DeJesus E, Lazzarin A, et al; STARTMRK Investigators. Safety and efficacy of raltegravir-based versus efavirenz-based combination therapy in treatment-naïve patients with HIV-1 infection: a multicentre, double-blind randomised controlled trial. Lancet. 2009; 374(9692):796-806.

61. Reynes J, Lawal A, Pulido F, et al. Lopinavir/ritonavir combined with raltegravir demonstrated similar antiviral efficacy and safety as lopinavir/ ritonavir combined with tenofovir disoproxil fumarate/emtricitabine in treatment-naïve HIV-1 infected subjects [abstract]. XVIII International AIDS Conference; 2010 Jul 18-23; Vienna, Austria.

62. Kozal M, Lupo S, DeJesus E, et al; SPARTAN Study Team. The SPARTAN study: a pilot study to assess the safety and efficacy of an investigational NRTI- and RTV-sparing regimen of atazanavir (ATV) experimental dose of $300 \mathrm{mg}$ BID plus raltegravir (RAL) $400 \mathrm{mg}$ BID (ATV+RAL) in treatment-naïve HIV-infected subjects [abstract]. XVIII International AIDS Conference; 2010 Jul 18-23; Vienna, Austria.

63. Powderly WG. Integrase inhibitors in the treatment of HIV-1 infection. J Antimicrob Chemother. 2010;65(12):2485-2488.

64. Cohen C, Shamblaw D, Ruane P, et al. Singlet-tablet, fixed-dose regimen of elvitegravir/emtricitabine/tenofovir disoproxil fumarate/ GS-9350 achieves a high rate of virologic suppression and GS-9350 is an effective booster [abstract]. 17th Conference on Retroviruses and Opportunistic Infections; 2010 Feb 16-19; San Francisco, CA.

65. Eron JJ, Young B, Cooper DA, et al; SWITCHMRK 1 and 2 Investigators. Switch to a raltegravir-based regimen versus continuation of a lopinavir-ritonavir-based regimen in stable HIV-infected patients with suppressed viraemia (SWITCHMRK 1 and 2): two multicentre, double-blind, randomised controlled trials. Lancet. 2010;375(9712): 396-407.

66. Martinez E, Larrousse M, Llibre JM, et al; SPIRAL Study Group. Substitution of raltegravir for ritonavir-boosted protease inhibitors in HIV-infected patients: the SPIRAL study. AIDS. 2010;24(11): 1697-1707.

67. Finzi D, Blankson J, Siliciano JD, et al. Latent infection of CD4+ T cells provides a mechanism for lifelong persistence of HIV-1, even in patients on effective combination therapy. Nat Med. 1999;5(5):512-517.

68. Palmer S, Maldarelli F, Wiegand A, et al. Low-level viremia persists for at least 7 years in patients on suppressive antiretroviral therapy. Proc Natl Acad Sci U SA. 2008;105(10):3879-3884.

69. Croteau D, Letendre S, Best BM, et al; CHARTER Group. Total raltegravir concentrations in cerebrospinal fluid exceed the 50-percent inhibitory concentration for wild-type HIV-1. Antimicrob Agents Chemother. 2010;54(12):5156-5160. 
70. Archin NM, Cheema M, Parker D, et al. Antiretroviral intensification and valproic acid lack sustained effect on residual HIV-1 viremia or resting CD4+ cell infection. PLoS One. 2010;5(2):e9390.

71. Gandhi R, Zheng S, Bosch R, et al. Raltegravir (RAL) intensification does not reduce low-level residual viremia in HIV-1-infected patients on antiretroviral therapy (ART): results from ACTG A5244 [abstract]. 5th IAS Conference on HIV Pathogenesis, Treatment and Prevention; 2009 Jul 19-22; Cape Town, South Africa.

72. Goethals O, Vos A, van Ginderen M, et al. Primary mutations selected in vitro with raltegravir confer large fold changes in susceptibility to first-generation integrase inhibitors, but minor fold changes to inhibitors with second-generation resistance profiles. Virology. 2010;402(2): 338-346.

73. Anies G, Da Silva D, Recordon-Pinson P, et al. Clonal analysis of raltegravir-resistant patterns including mutations at positions 143 and 155 [abstract]. 16th Conference on Retroviruses and Opportunistic Infections; 2009 Feb 8-11; Montreal, Canada.

74. Goethals O, Clayton R, van Ginderen M, et al. Resistance mutations in human immunodeficiency virus type 1 integrase selected with elvitegravir confer reduced susceptibility to a wide range of integrase inhibitors. J Virol. 2008;82(21):10366-10374.

75. Miller MD, Danovich RM, Ke Y, et al; on behalf of the P005 Study Team. Longitudinal analysis of resistance to the HIV-1 integrase inhibitor raltegravir: results from P005, a phase II study in treatmentexperienced patients [abstract]. Antivir Ther. 2008;13 Suppl 3:A8.
76. $\mathrm{Hu} \mathrm{Z}$, Kuritzkes DR. Effect of raltegravir resistance mutations in HIV-1 integrase on viral fitness. J Acquir Immune Defic Syndr. 2010; 55(2):148-155.

77. Geretti AM, Fearnhill E, Ceccherini-Silberstein F, et al. Prevalence and patterns of raltegravir resistance in treated patients in Europe [abstract]. Antivir Ther. 2010;15 Supp1 2:A62.

78. Blanco JL, Buzon MJ, Calvo M, et al. Evolution of viral load and integrase resistance mutations after interrupting raltegravir (RAL) in HIV-infected subjects with virological failure on a RAL-containing regimen: the Raldyn study [abstract]. Antivir Ther. 2010;15 Suppl 2: A133.

79. Baldanti F, Paolucci S, Gulminetti R, Brandolini M, Barbarini G, Maserati R. Early emergence of raltegravir resistance mutations in patients receiving HAART salvage regimens. J Med Virol. 2010;82(1): 116-122.

80. McColl DJ, Fransen S, Gupta S, et al. Resistance and cross-resistance to first generation integrase inihibitors: insights from a Phase II study of elvitegravir (GS-9137) [abstract]. Antivir Ther. 2007;12 Suppl 1:S11.

81. Gallien $\mathrm{S}$, Delaugerre $\mathrm{C}, \mathrm{Hu} \mathrm{Z}$, et al. Integrase inhibitor resistance mutations in treatment-experienced HIV-1-infected patients with lowlevel viraemia receiving raltegravir-containing antiretroviral therapy: an ANRS 138-EASIER Trial substudy [abstract]. Antivir Ther. 2010;15 Suppl 2:A60
Infection and Drug Resistance

\section{Publish your work in this journal}

Infection and Drug Resistance is an international, peer-reviewed openaccess journal that focuses on the optimal treatment of infection (bacterial, fungal and viral) and the development and institution of preventive strategies to minimize the development and spread of resistance. The journal is specifically concerned with the epidemiology of antibiotic

\section{Dovepress}

resistance and the mechanisms of resistance development and diffusion in both hospitals and the community. The manuscript management system is completely online and includes a very quick and fair peerreview system, which is all easy to use. Visit http://www.dovepress.com/ testimonials.php to read real quotes from published authors. 